\title{
Attenuation of TNF-driven murine ileitis by intestinal expression of the viral immunomodulator CrmD
}

\author{
A Viejo-Borbolla ${ }^{1,2,6}$, AP Martin ${ }^{1,6,7}$, LR Muniz ${ }^{1}$, L Shang ${ }^{1}$, F Marchesi $^{1}$, N Thirunarayanan ${ }^{1}, \mathrm{~N} \mathrm{Harpaz}^{3}$,

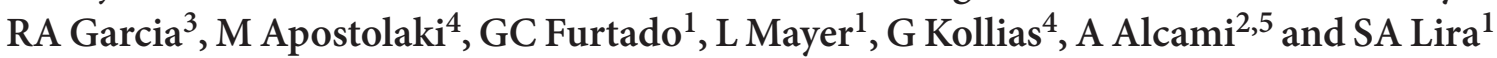

Tumor necrosis factor $\alpha(T N F \alpha)$ is a key pathogenic factor in Crohn's disease and rheumatoid arthritis. TNF $\triangle A R E$ mice express high levels of TNF $\alpha$ and present Crohn's-like ileitis and arthritis. Alterations in the chemokine network could underline the TNF-driven ileitis. The aim of this study was to evaluate the role of TNF and chemokines in ileitis using ectromelia virus cytokine response modifier $\mathrm{D}(\mathrm{CrmD})$, a protein that binds TNF $\alpha$ and a limited number of chemokines. We generated transgenic mice expressing $\mathrm{CrmD}$ in intestinal epithelial cells ( $\mathrm{VCrmD}$ mice) and crossed them with the TNF ${ }^{\triangle A R E}$ mice to test whether CrmD could affect TNF-driven inflammatory processes. During homeostasis, only the number of $B$ cells in the lamina propria was reduced by $\mathrm{CrmD}$ expression. Interestingly, CrmD expression in the intestine markedly attenuated the inflammatory infiltrates in the ileum of TNF $\triangle A R E$ mice, but did not affect development of arthritis. Our results suggest that CrmD affects development of ileitis by locally affecting both TNF and chemokine function in the ileum.

\section{INTRODUCTION}

The immune system within the mucosa is one of the first barriers to recognize and respond to pathogens, and relies upon a controlled interplay between gut epithelial and immune cells. ${ }^{1}$ Cytokines are essential mediators of the interactions between activated cells and nonimmune cells, including epithelial, endothelial, and mesenchymal cells. Tumor necrosis factor $\alpha(\mathrm{TNF} \alpha)$ has pleiotropic effects affecting both innate and adaptive responses through the induction of cytokines and chemokines, which recruit inflammatory leukocytes, and the activation of the mucosal endothelium. ${ }^{2,3}$ Alterations in the expression levels of TNF $\alpha$ are associated with several immune-related disorders including inflammatory bowel disease (IBD) and rheumatoid arthritis. IBD is characterized by continuous inflammatory reactions leading to the disruption of the intestinal epithelial barrier. IBD includes ulcerative colitis (UC) and Crohn's disease (CD). TNF $\alpha$ overexpression is observed in patients suffering from arthritis, $\mathrm{CD}$, and ulcerative colitis, many of whom have been successfully treated with antiTNF drugs. ${ }^{4-7}$ However, better immunomodulators are required to improve the outcome of the treatment.
Several animal models have been developed to study IBD, ${ }^{8}$ including the $\mathrm{TNF}^{\triangle \mathrm{ARE}}$ mouse model. $\mathrm{TNF}^{\triangle \mathrm{ARE}}$ mice lack the AU-rich element that destabilizes the TNF mRNA in the $3^{\prime}$ - untranslated region of the TNF gene, ${ }^{9}$ and therefore, stromal and bone marrow-derived cells from the TNF ${ }^{\triangle \mathrm{ARE}}$ mice express high levels of TNF $\alpha$ mRNA and protein under basal conditions and upon stimulation with lipopolysaccharide. ${ }^{9} \mathrm{TNF}^{\triangle \mathrm{ARE}}$ mice develop Crohn's-like IBD and arthritis and express cytokines that are also found in human CD patients. ${ }^{9,10}$ The Crohn's-like IBD observed in the $\mathrm{TNF}^{\triangle \mathrm{ARE}}$ mice is highly penetrant and restricted to the terminal ileum. The first signs of ileitis are observed at 6-8 weeks of age in both sexes. ${ }^{9,10}$

The effector mechanisms associated with TNF function that account for the marked inflammatory infiltrates observed in the $\mathrm{TNF}^{\triangle \mathrm{ARE}}$ mice are still not defined. They could include generalized activation of endothelium and the increased expression of factors involved in cell recruitment, such as chemokines, small, basic, chemoattractant cytokines that have a pivotal role in the recruitment of leukocytes during development, homeostasis, and inflammation. Chemokines are classified into C, CC, CXC, and

\footnotetext{
${ }^{1}$ Immunology Institute, Mount Sinai School of Medicine, New York, New York, USA. ${ }^{2}$ Centro de Biología Molecular Severo Ochoa (Consejo Superior de Investigaciones Científicas-UAM), Cantoblanco, Madrid, Spain. ${ }^{3}$ Department of Pathology, Mount Sinai School of Medicine, New York, New York, USA. ${ }^{4}$ Institute of Immunology, Biomedical Sciences Research Center "Alexander Fleming", Vari, Greece. ${ }^{5}$ Department of Medicine, University of Cambridge, Addenbrooke's Hospital, Cambridge, UK. ${ }^{6}$ Both authors contributed equally to this work. ${ }^{7}$ Present address: Eli Lilly and Company, Lilly Corporate Center, Indianapolis, Indiana, USA. Correspondence: SA Lira (sergio.lira@mssm.edu) 
CX3C subfamilies according to the relative positioning of the $\mathrm{N}$-terminal cysteine residues. ${ }^{11}$ Most chemokines are secreted, with the exception of CXCL16 and CX3CL1, which contain a transmembrane domain. ${ }^{11}$ To date, however, there is no direct evidence that chemokines are effectors in TNF-driven diseases.

In this study, we probe into the role of TNF and chemokines in ileitis using a virus-derived immunomodulatory protein: the cytokine response modifier $\mathrm{D}(\mathrm{CrmD})$. CrmD is encoded by ectromelia virus (ECTV), an orthopoxvirus that causes mousepox and is closely related to the human pathogens variola virus and monkeypox virus. Variola virus and monkeypox virus encode a related protein $\mathrm{CrmB}$. CrmD and $\mathrm{CrmB}$ bind with high affinity to human, mouse, and rat TNF $\alpha$, mouse LT $\alpha$, and a small group of $\mathrm{CC}$ and CXC chemokines. ${ }^{12} \mathrm{CrmD}$ and $\mathrm{CrmB}$ inhibit both TNF $\alpha$ cytotoxic effect and chemotaxis in vitro. ${ }^{12}$ Several studies with poxvirus models of infection have shown that $\mathrm{CrmB}$ and other related poxvirus TNF receptors ( $\mathrm{CrmC}, \mathrm{CrmE}$, and $\mathrm{T} 2$ ) contribute to virus virulence, and it has been suggested that these viruses may use the secreted TNF $\alpha$ receptors to reduce inflammatory responses during infection. ${ }^{13}$ Studies conducted with recombinant variola virus or monkeypox virus $\mathrm{CrmB}$ indicate a protective effect in lipopolysaccharide-induced shock ${ }^{14}$ showing a role for $\mathrm{CrmB}$ in the inhibition of the innate immune response. To date, there is no information regarding the potential use of $\mathrm{CrmD} / \mathrm{B}$ as an immunomodulator during homeostasis or chronic inflammation.

We have investigated the role of $\mathrm{CrmD}$ in vivo by expressing $\mathrm{CrmD}$ in mouse intestinal epithelial cells (IECs). Expression of
CrmD only affected the B-cell population within the intestinal LP during homeostasis. However, CrmD expression markedly reduced all leukocyte populations observed in the ileum of the $\mathrm{TNF}^{\triangle \mathrm{ARE}}$ mice. ${ }^{9}$ These changes were associated with reduced expression of many chemokines shown to be upregulated in the ileum of TNF $\triangle \mathrm{ARE}$ mice. Together these results show that CrmD blocks development of TNF $\alpha$-driven inflammation and that TNF $\alpha$ causes intestinal inflammation through upregulation of chemokines.

\section{RESULTS}

\section{Chemokines responsible for leukocyte recruitment are upregulated in the ileum of the TNF ${ }^{\triangle A R E}$ mice}

$\mathrm{TNF}^{\triangle \mathrm{ARE}}$ mice have rich inflammatory cell infiltrates in the ileum that are absent in wild-type (WT) mice. To date, there is no information regarding the pattern of chemokine expression and its potential implication in the recruitment of the inflammatory infiltrates in this model of TNF-driven disease. To examine if the previously observed cellular changes were associated with modifications in the expression pattern of chemokines, we extracted total RNA from the distal $5 \mathrm{~cm}$ of the small bowel of 11- and 13week-old age-matched $\mathrm{WT}$ and $\mathrm{TNF}^{\triangle \mathrm{ARE}}$ mice and examined the relative mRNA levels of all murine chemokines by quantitative-PCR (q-PCR). TNF $\triangle A R E$ mice expressed significantly higher levels of CC chemokines (CCL2, CCL7, CCL8, CCL9/10, CCL17, CCL19, CCL20, CCL21, and CCL22) than WT mice (Figure 1a). CXC chemokines CXCL1, CXCL2, CXCL4, CXCL9,
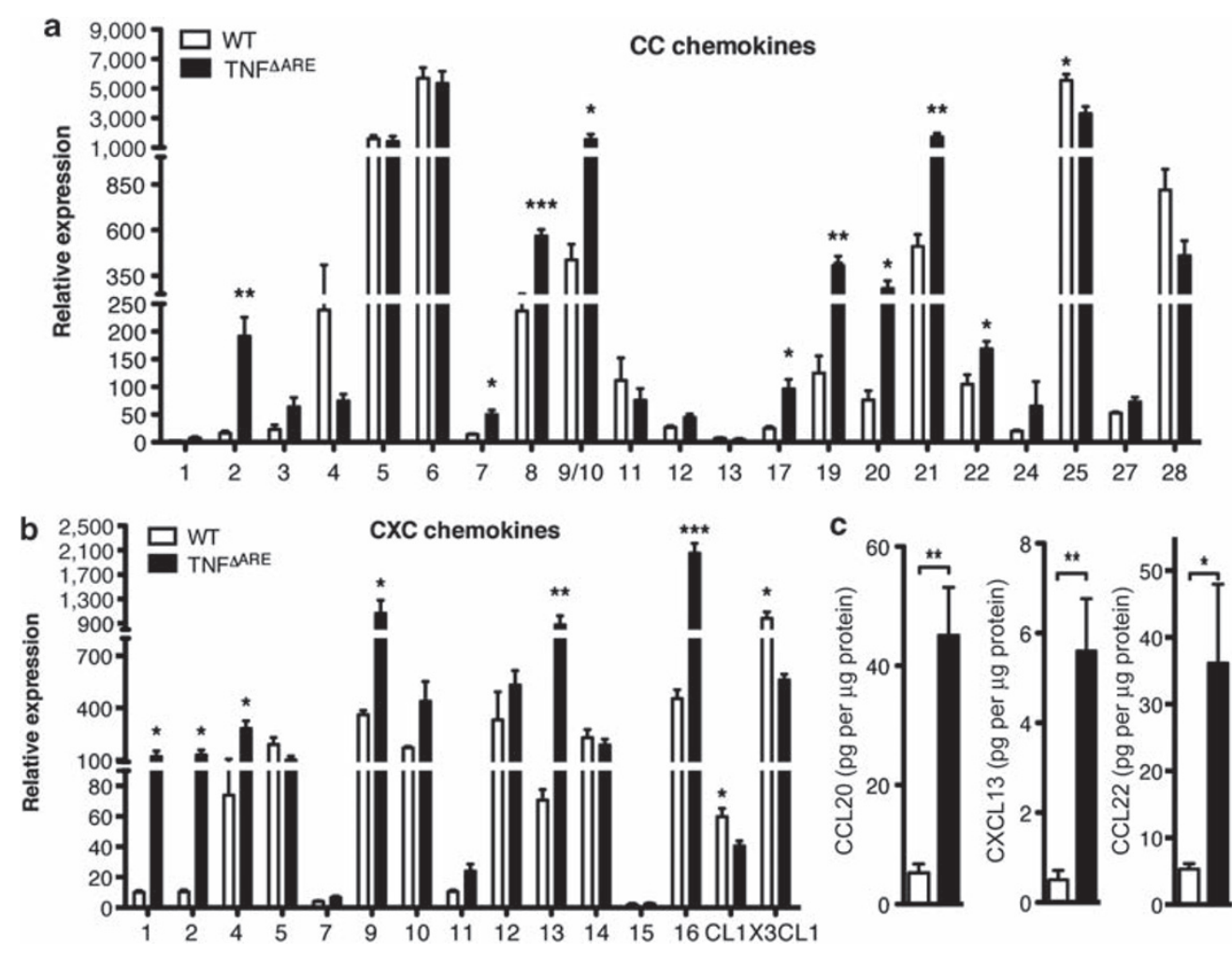

Figure 1 Analysis of chemokine expression patterns in the ileum of TNF $\triangle A R E$ mice. (a and $\mathbf{b})$ Differential expression of CC (a) and CXC (b) chemokines in the ileum of tumor necrosis factor (TNF) $\triangle$ ARE and wild-type (WT) mice $(n=3$, normalized to ubiquitin). The expression of several chemokines is increased in the ileum of TNF ${ }^{\triangle A R E}$ mice. ( $\left.{ }^{\star} P<0.05,{ }^{\star \star} P<0.01,{ }^{\star \star \star} P<0.001\right)$. (c) CCL20, CXCL13, and CCL22 protein levels in extracts from the terminal ileum of TNF $\triangle \mathrm{ARE}(n=5)$ and WT mice $(n=3)\left({ }^{\star \star} P<0.01\right)$. 
Table 1 Average fold increase in chemokine expression in the ileum of TNF $\triangle$ ARE mice compared to WT mice

\begin{tabular}{lccc}
\hline CCL & Fold increase & CXCL & Fold increase \\
\hline 1 & 2.8 & 1 & 12.1 \\
2 & 11.7 & 2 & 12.6 \\
3 & 2.8 & 4 & 3.8 \\
4 & 0.3 & 5 & 0.5 \\
5 & 0.9 & 7 & 1.6 \\
6 & 0.9 & 9 & 2.9 \\
7 & 3.6 & 10 & 2.6 \\
8 & 2.4 & 11 & 2.3 \\
$9 / 10$ & 3.5 & 12 & 1.6 \\
11 & 0.7 & 13 & 12.4 \\
12 & 1.7 & 14 & 0.8 \\
13 & 0.7 & 15 & 1.3 \\
17 & 3.9 & 16 & 4.5 \\
19 & 3.2 & & Fold increase \\
20 & 3.7 & CL & 0.7 \\
21 & 3.4 & 1 & Fold increase \\
22 & 1.6 & & \\
24 & 3.3 & $\mathbf{C X 3 C L}$ & \\
25 & 0.6 & 1 & \\
27 & 1.4 & & \\
\hline
\end{tabular}

CXCL13, and CXCL16 were also significantly upregulated in the $\mathrm{TNF}^{\triangle \mathrm{ARE}}$ ileum (Figure 1b). However, CL1 and CX3CL1 expression was downregulated $(P<0.05$, Figure $\mathbf{1 b})$. The fold increase in chemokine expression observed is shown in Table 1. To assess whether some of the chemokines were indeed significantly augmented, we analyzed CCL20, CCL22, and CXCL13 protein levels in ileum extracts from $\mathrm{WT}$ and $\mathrm{TNF}^{\triangle \mathrm{ARE}}$ mice by enzyme-linked immunosorbent assay. As shown in Figure 1c, all three chemokines were found significantly increased in the terminal ileum of TNF ${ }^{\triangle \mathrm{ARE}}$ mice $(P<0.005)$. These results indicate that several chemokines are markedly upregulated in the ileum of $\mathrm{TNF}^{\triangle \mathrm{ARE}}$ mice.

\section{Generation of transgenic mice expressing CrmD in the IEC}

TNF $\alpha$ has a pivotal role in the inflammatory process observed in $\mathrm{TNF}^{\triangle \mathrm{ARE}}$ mice. CrmD interacts with high affinity with TNF $\alpha$, LT $\alpha$, and a subset of chemokines, including mCCL20, mCCL25, mCCL27, mCCL28, mCXCL11, mCXCL12 $\beta$, mCXCL13, and CXCL14 $^{12}$ (A.A., unpublished data). CrmD inhibits both the cytotoxic effect of TNF $\alpha$ and hCCL25-mediated chemotaxis in vitro. ${ }^{12}$

To analyze the potential immunomodulatory role of $\mathrm{CrmD}$ in vivo during homeostasis and inflammation, we expressed it under the control of the villin promoter (vCrmD), targeting its expression to the IEC of both the small and large bowel. ${ }^{15} \mathrm{We}$ obtained four vCrmD founders from which three lines $(1,2$, and 6) were derived. Expression of CrmD mRNA was assessed by q-PCR. Line 1 expressed the highest level of mRNA followed by lines 6 and 2 (Figure 2a). CrmD expression was detected by immunofluorescence in the crypts and epithelial cells in the jejunum of lines 1 and 6 (Figure $2 c$ and not shown) but not in the intestine of WT mice (Figure 2b). Because CrmD is secreted, positive staining was also observed in the intestinal LP (Figure 2c). vCrmD mice were healthy, reproduced well, and did not display any gross abnormalities.

\section{Expression of CrmD in the intestinal epithelium decreases number of B cells within the LP}

Then we analyzed the effect of CrmD expression on the leukocyte populations of the intestine LP during homeostasis. Age-matched WT and vCrmD mice from line 1 were used. Leukocytes were isolated from the LP of the small and large bowel, including the cecum, as previously described, ${ }^{15}$ and the different leukocyte populations were analyzed by flow cytometry. LP from WT mice harbors B, T, and myeloid cells. ${ }^{16}$ Myeloid cells can be subdivided by analyzing the cell-surface markers CD11b and CD11c. One population is characterized by expression of high levels of CD11c and major histocompatibility complex (MHC) class II (MHCII) (Supplementary Figure 1c online, $\left.\mathrm{CD} 11 \mathrm{~b}^{+} / \mathrm{CD} 11 \mathrm{c}^{\text {high }}\right)$ whereas the other has low levels of CD11c (CD11b+/CD11 clow $)$. The CD11b+/CD11 ${ }^{\text {low }}$ population can be further analyzed and subdivided into three subsets depending on the expression of MHCII and Gr-1. In WT mice, the majority ( $>70 \%$ ) of the $\mathrm{CD} 11 \mathrm{~b}^{+} / \mathrm{CD} 11 \mathrm{c}^{\text {low }}$ cells are eosinophils ( $\mathrm{MHCII}{ }^{\text {low or null }} / \mathrm{Gr}-1^{\text {low }}$ ). The remaining cells are neutrophils (No, MHCII ${ }^{\text {low }} / \mathrm{Gr}-1^{\text {high }}$ ) and macrophages (Mac, MHCII $\left.{ }^{\text {high }} / \mathrm{Gr}-1^{\text {low }}\right){ }^{17}$

Expression of CrmD did not affect the T- or B-cell relative numbers, whereas it resulted in a significant $(P<0.05)$ reduction in total B-cell numbers in the LP of vCrmD mice compared to controls (Figure 2e). To investigate which B-cell population was decreased, we looked for immunoglobulin M (IgM)- and IgA-producing cells and we found that relative and absolute numbers of $\operatorname{IgM}^{+}$B cells were decreased in vCrmD transgenic mice (Supplementary Figure 1a and $\mathbf{b}$ online). Further analysis did not reveal any significant differences in the relative (Supplementary Figure 1c online) or absolute number (Supplementary Figure 1d online) of the other leukocyte populations within the LP of the small bowel of $\mathrm{vCrmD}$ compared to WT mice. We did not observe differences in relative or absolute number of leukocytes in the LP of the large bowel (not shown). The intraepithelial lymphocyte (IEL) compartment of both small and large bowel and the Peyer's patch (PP) did not present significant changes either (not shown). Conventional histological analysis of the different segments of the intestine of vCrmD mice did not reveal any gross morphological abnormality (not shown). To investigate the mechanisms by which CrmD affected selectively B-cell recruitment, we analyzed the effect of CrmD on chemokine expression (Figure $\mathbf{2} \mathbf{f}$ and $\mathbf{g}$ ) and chemotaxis (Figure 2h). CrmD expression did not affect the expression of most chemokines. However, significant changes were observed in the expression of a few chemokines (CCL5, CCL8, CCL22, CXCL9, CCL25, and CX3CL1), most notably 
a

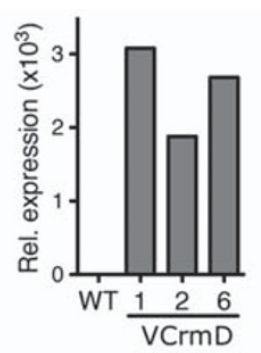

d
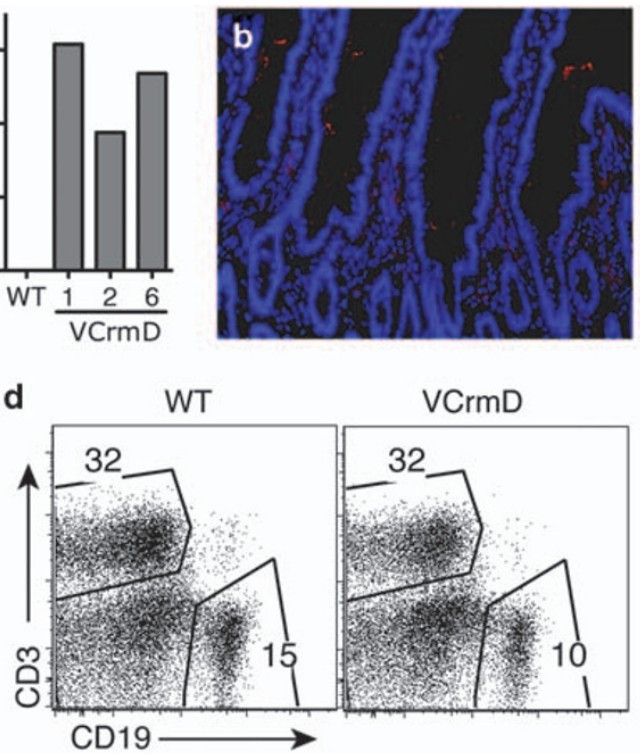

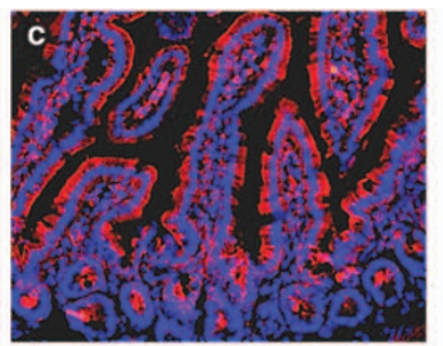

e

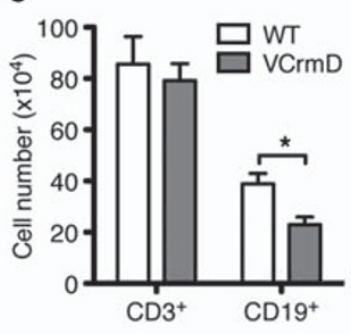

\section{$\mathbf{f}$}
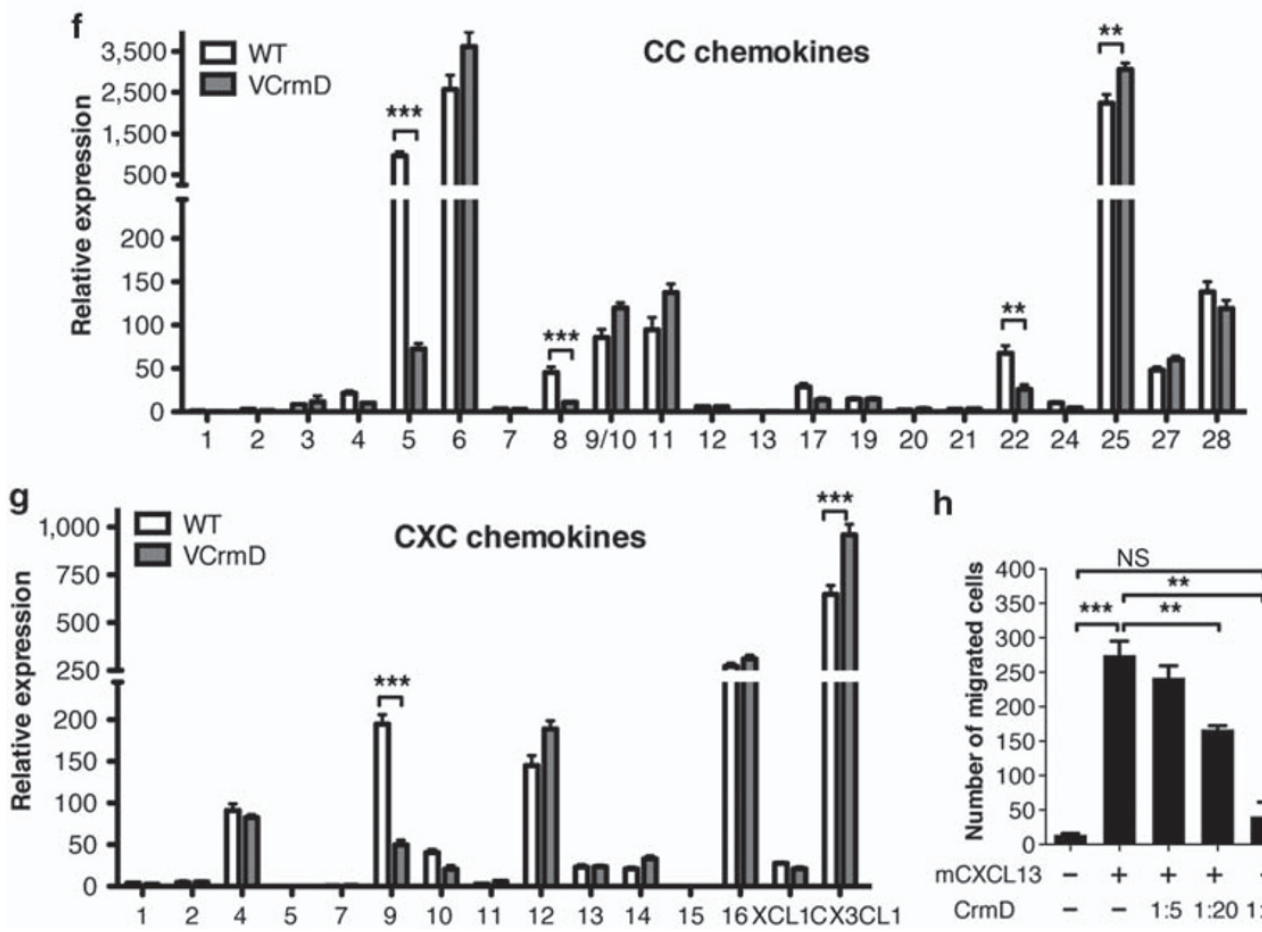

h

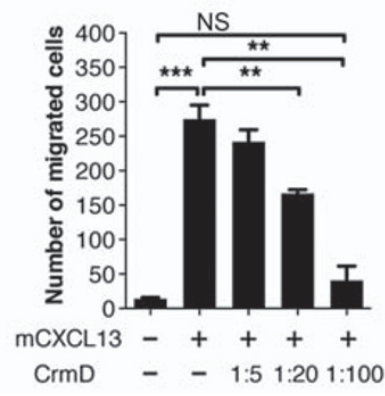

Figure 2 The effect of transgenic expression of cytokine response modifier $\mathrm{D}(\mathrm{CrmD})$ on leukocyte subsets in the lamina propria (LP). (a) CrmD mRNA expression in different lines of $\mathrm{vCrmD}$ mice. The values were normalized to ubiquitin in each sample. (b and $\mathbf{c})$ Immunostaining of $\mathrm{CrmD}$ in the small intestine of wild-type (WT) (b) and vCrmD (c) mice. (d) Representative FACS analysis of T and B cells within the LP of vCrmD and WT mice. (e) Absolute cell number of T and B cells in vCrmD mice within the CD45 ${ }^{+}$cell subset $\left(n=5\right.$ for each group; $\left.{ }^{*} P<0.05\right)$. (f and $\left.\mathbf{g}\right)$ Differential expression of CC (f) and CXC (g) chemokines in the ileum of vCrmD and WT mice $\left(n=3\right.$, normalized to ubiquitin; ${ }^{* \star} P<0.01$, $\left.{ }^{* * *} P<0.001\right)$. (h) CrmD inhibition of mCXCL13-mediated chemotaxis. Isolated splenocytes were incubated with $100 \mathrm{~nm} \mathrm{mCXCL} 13$ in transwell plates in the absence or presence of CrmD. The molar ratio $\mathrm{mCXCL} 13 / \mathrm{CrmD}$ is indicated. The number of migrated cells is represented. CrmD is able to significantly $(P<0.01)$ inhibit $\mathrm{mCXCL13-}$ mediated chemotaxis in a dose-dependent manner. One representative experiment of three, performed in triplicate, is shown.

(over threefold changes) CCL5 and CXCL9. These changes did not result in reduction of cell recruitment probably because of the redundancy of the chemokine network and the higher expression level of other chemokines involved in T-cell recruitment such as CCL25. The expression of the main chemokines involved in B-cell recruitment (CCL20, CCL21, CXCL12, and CXCL13) was not affected by CrmD. To test if the changes in the number of $\mathrm{B}$ cells observed in the $\mathrm{vCrmD}$ mice could be due to direct inhibition of B-cell chemoattractants, we performed chemotaxis experiments with splenic B cells and CXCL13. As shown in Figure $\mathbf{2 h}, \mathrm{CrmD}$ inhibited chemotaxis mediated by mCXCL13 in a dose-dependent manner, suggesting that the reduced levels of $\mathrm{B}$ cells in the intestine of $\mathrm{vCrmD}$ mice could result from direct inhibition of chemokine function by CrmD. 
Together these results indicate that CrmD expression by IEC induced a decrease in B-cell population probably by direct inhibition of CXCL13 function but did not significantly alter most leukocyte populations in the gut.

\section{Expression of CrmD by IEC reduces the inflammatory infiltrates present in the ileum of the TNF ${ }^{\triangle A R E}$ mice}

To study the effect of CrmD on a TNF $\alpha$-driven chronic inflammatory process, we crossed $\mathrm{vCrmD}$ mice from line 1 with $\mathrm{TNF}^{\triangle \mathrm{ARE}}$ mice, ${ }^{9}$ to obtain mice $\mathrm{CrmD}$ transgenic and heterozygous for $\mathrm{TNF}^{\triangle \mathrm{ARE}}$ (CrmD/TNF ${ }^{\triangle \mathrm{ARE}}$ mice). Heterozygous $\mathrm{TNF}^{\triangle \mathrm{ARE}}$ mice develop Crohn's-like disease in the terminal ileum and inflammatory arthritis, because of an intrinsic defect in the posttranscriptional regulation of TNF $\alpha$ mRNA. ${ }^{9}$

Expression of CrmD during homeostasis ( $\mathrm{vCrmD}$ mouse) did not result in histological changes with respect to control littermates (not shown). To evaluate if epithelial expression of CrmD would affect the pathology observed in the intestine of $\mathrm{TNF}^{\mathrm{ARE}}$ mice, we analyzed the terminal ileum of age-matched $\mathrm{WT}(n=3), \mathrm{TNF}^{\Delta \mathrm{ARE}}(n=15)$, and $\mathrm{CrmD} / \mathrm{TNF}^{\Delta \mathrm{ARE}}(n=9)$ (10- to 14-week old). As expected, the ileum of $\mathrm{TNF}^{\triangle \mathrm{ARE}}$ mice displayed histopathological changes characteristic of IBD such as villus blunting, mucosal, and submucosal inflammation with the presence of No and lymphoplasmacytic infiltrates (Figure 3a). Patchy transmural inflammation and the appearance of lymphoid aggregates and granulomata were also observed (not shown). These criteria were individually analyzed and scored semiquantitavely (see Methods section). Interestingly, histological analysis of the terminal ileum from $\mathrm{CrmD} / \mathrm{TNF}^{\triangle \mathrm{ARE}}$ mice revealed significant changes in the inflammatory pathology. Although mucosal abnormalities were still observed, the intestinal inflammation was significantly decreased by CrmD expression (Figure 3a and $\mathbf{b}$ ). There was improvement of the villus blunting, decrease in the density of mucosal and submucosal inflammatory infiltrates and in the number of lymphoid aggregates. This reduction in inflammation occurred despite the continuous and constitutive expression of TNF $\alpha$ by stromal and hematopoietic cells in the $\mathrm{TNF}^{\triangle \mathrm{ARE}}$ mice. ${ }^{9}$

To test whether CrmD expression in the intestine could affect disease development in the periphery, we analyzed joints from WT $(n=5), \mathrm{TNF}^{\triangle \mathrm{ARE}}(n=9)$, and $\mathrm{CrmD}^{\mathrm{T}} \mathrm{TNF}^{\triangle \mathrm{ARE}}$ $(n=9)$ mice at $10-14$ weeks of age. In agreement with previous reports, ${ }^{9}$ the joints of TNF $\triangle \mathrm{ARE}$ mice displayed severe pathological features of chronic inflammatory arthritis, including hyperplasia of the synovial membrane and presence of polymorphonuclear infiltrates. We also observed pannus and fibrous tissue formation, subchondral bone erosion, and articular cartilage destruction (Figure $\mathbf{3 a}$ and $\mathbf{c}$ ). At the histological level, $\mathrm{CrmD} / \mathrm{TNF}^{\triangle \mathrm{ARE}}$ mice exhibited the same features observed in $\mathrm{TNF}^{\triangle \mathrm{ARE}}$ littermate controls (Figure 3a and $\mathbf{c}$ ), suggesting that the $\mathrm{CrmD}$ inhibitory properties were restricted to the intestine.

TNF-driven ileitis is associated with the marked reduction of CD8 $\alpha \alpha$-expressing IELs and the increased representation of conventional CD $8 \alpha \beta$ IELs. ${ }^{18}$ To evaluate if $\mathrm{CrmD}$ expression in IEC alters the phenotype observed in the IEL of TNF $\triangle A R E$ mice, we performed flow cytometry. IEL from the ileum of control mice consist primarily of $\mathrm{CD} 8^{+} \mathrm{T}$ cells with a low percentage of $\mathrm{CD} 4^{+} \mathrm{T}$ cells (Figure $4 \mathrm{a}$ left). $\mathrm{CD} 8^{+} \mathrm{T}$ cells can be divided in CD $8 \alpha \beta$ T cells and CD $8 \alpha \alpha$ T cells, which include both TCR $\alpha \beta$ and TCR $\gamma \delta$ T cells. As expected, $\mathrm{TNF}^{\triangle \mathrm{ARE}}$ mice showed a decrease in the relative number (Figure 4a left) as well as in the absolute number of CD $8 \alpha \alpha$ T cells and an increase in the $\mathrm{CD} 8 \alpha \beta$ and CD4 populations (Figure 4a right). Expression of CrmD corrected most of the changes induced by TNF expression, with the exception of those associated with $\mathrm{CD} 4^{+} \mathrm{T}$ cells
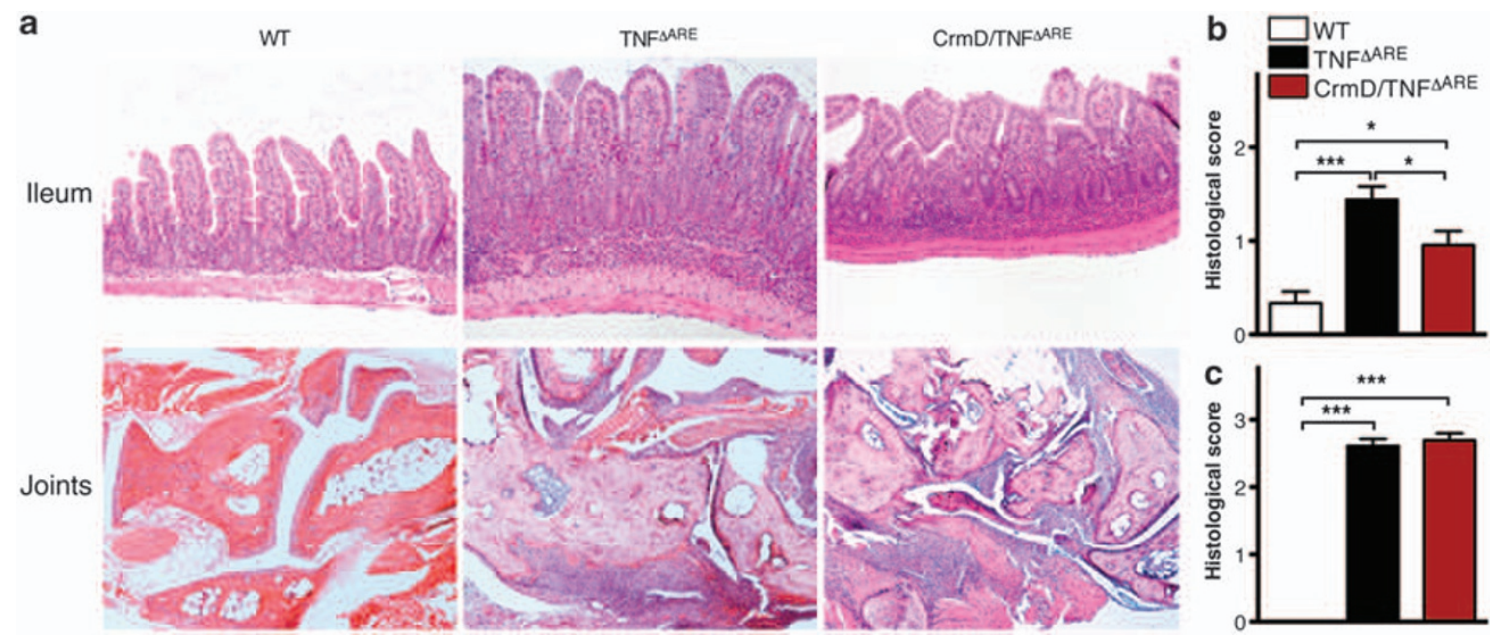

Figure 3 Cytokine response modifier $\mathrm{D}(\mathrm{CrmD})$ expression reduces the inflammation observed in the ileum but not in the joints of tumor necrosis factor (TNF) $\triangle$ ARE mice. (a) Representative pictures of the terminal ileum (upper panel) and joints (lower panel) of wild-type (WT; left), TNF ${ }^{\triangle A R E}$ (middle), and CrmD/TNF $\triangle$ ARE (right) mice. Notice the reduction of inflammation observed in the ileum of CrmD/TNF $\triangle A R E$ (right) mice compared to that of TNF $\triangle A R E$ (middle) and the formation of the inflammatory pannus and areas of cartilage and bone erosion in the joints from both TNF $\triangle A R E$ and $\mathrm{CrmD} / \mathrm{TNF}^{\triangle A R E}$ mice. (b) Histological score indicating the development of intestinal inflammation based on the analysis of WT $(n=3)$, TNF $\triangle A R E(n=15)$, and $\mathrm{CrmD} / \mathrm{TNF}^{\triangle \mathrm{ARE}}(n=9)$ mice. (c) Histological score indicating the development of joint inflammation based on the analysis of WT ( $\left.n=5\right)$, TNF $\triangle \mathrm{ARE}$ $(n=9)$, and $\mathrm{CrmD} / \mathrm{TNF}^{\Delta \mathrm{ARE}}(n=9)$ mice $\left({ }^{\star} P<0.05,{ }^{\star \star *} P<0.001\right)$. 
and CD $8 \alpha \alpha^{+} \mathrm{TCR} \gamma \delta^{+} \mathrm{T}$ cells whose values were significantly different from those found in controls (Figure 4a).

We then purified the LP leukocyte populations from the ileum of WT, TNF ${ }^{\triangle A R E}$, and CrmD/TNF ${ }^{\triangle A R E}$ mice (8- to 11-week old) and analyzed the different populations by flow cytometry. In normal LP, the relative number of $\mathrm{CD}^{+} \mathrm{T}$ cells is higher than the number of $\mathrm{CD} 19^{+} \mathrm{B}$ cells (Figure $4 \mathrm{~b}$ left). This relation is altered in the TNF ${ }^{\triangle \mathrm{ARE}}$ mice, which have proportionally more $\mathrm{B}$ than $\mathrm{T}$ cells. The total numbers of $\mathrm{B}$ and $\mathrm{T}$ cells in $\mathrm{TNF}^{\triangle \mathrm{ARE}}$ mice were significantly higher than those found in WT mice $(P<0.05$ and $<0.005$, respectively) (Figure $4 \mathbf{b}$ right). TNF ${ }^{\triangle A R E}$ mice showed a higher percentage of $\mathrm{CD} 4^{+}$cells and a lower percentage of $\mathrm{CD} 8{ }^{+}$cells compared to WT mice $(P<0.005$, Figure $4 \mathrm{cleft})$, consistent with previous studies. ${ }^{18}$ The absolute cell numbers of these cell populations were also increased $\left(\mathrm{CD} 4^{+} P<0.0005\right.$, and $\mathrm{CD}^{+} P<0.005$, Figure $4 \mathrm{c}$ right). Expression of CrmD markedly attenuated the changes associated with TNF $\alpha$ expression. There was no difference between $\mathrm{WT}$ and $\mathrm{CrmD} / \mathrm{TNF}^{\triangle \mathrm{ARE}}$ mice in the total cell number of $\mathrm{CD} 8^{+}$cells. However, the absolute number of $\mathrm{CD}^{+}, \mathrm{CD}_{1} 9^{+}$, and $\mathrm{CD} 4^{+} \mathrm{T}$ cells was higher in $\mathrm{CrmD} / \mathrm{TNF}^{\mathrm{ARE}}$ mice than in WT mice $(P<0.05$ and $<0.005$, respectively). $\mathrm{CrmD} / \mathrm{TNF}^{\triangle \mathrm{ARE}}$ mice presented fewer $\mathrm{T}$ and $\mathrm{B}$ cells than $\mathrm{TNF}^{\triangle \mathrm{ARE}}$ mice (Figure $4 \mathbf{b}$ ). $\mathrm{CrmD} / \mathrm{TNF}^{\triangle \mathrm{ARE}}$ mice had a reduction in the total cell number of $\mathrm{CD}^{+}(P<0.005)$, $\mathrm{CD}_{19}{ }^{+}(P<0.05), \mathrm{CD}^{+}(P<0.005)$, and $\mathrm{CD}^{+}(P<0.05)$ cells in the ileum compared to the TNF ${ }^{\triangle A R E}$ mice (Figure $4 b$ and $c$ ). The ratio of $\mathrm{CD} 4^{+} / \mathrm{CD}^{+}$cells in the $\mathrm{CrmD} / \mathrm{TNF}^{\Delta \mathrm{ARE}}$ mice was similar to that observed in the $\mathrm{TNF}^{\triangle \mathrm{ARE}}$ mice.

Analysis of the myeloid cell populations in the distal ileum showed that the relative and absolute number of $\mathrm{CD} 11 \mathrm{~b}^{+} /$ $\mathrm{CD} 11 c^{\text {low }}, \mathrm{CD}_{11} \mathrm{~b}^{+} / \mathrm{CD} 11 \mathrm{c}^{\text {high }}$, and $\mathrm{CD} 11 \mathrm{~b}^{-} / \mathrm{CD} 11 \mathrm{c}^{+}$cells was increased in the $\mathrm{TNF}^{\triangle \mathrm{ARE}}$ compared to WT mice $(P<0.0005$, Figure 4d). Interestingly, the absolute number of all these subsets was markedly reduced in $\mathrm{CrmD} / \mathrm{TNF}^{\triangle \mathrm{ARE}}$ mice compared to $\mathrm{TNF}^{\triangle \mathrm{ARE}}$ mice $(P<0.005$, Figure $4 \mathrm{~d}$ right). Analysis of the

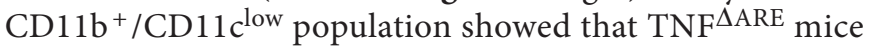
had more No, eosinophils, and Mac than WT mice $(P<0.005$, Figure 4e). The absolute numbers of these cells were markedly decreased in $\mathrm{CrmD} / \mathrm{TNF}^{\triangle \mathrm{ARE}}$ mice compared to $\mathrm{TNF}^{\triangle \mathrm{ARE}}$ mice (Figure 4e right). These results indicate that expression of $\mathrm{CrmD}$ in the intestine significantly reduced the inflammatory infiltrates promoted by TNF $\alpha$.

\section{Effect of CrmD expression is associated with a reduction of $\mathrm{CD}_{44}{ }^{+} \mathrm{T}$ cells in lamina propria leukocyte and mesenteric lymph node}

It was recently reported that dysregulated production of TNF results in the expansion of both $\mathrm{CD} 8^{+}$and $\mathrm{CD} 4^{+}$ $\mathrm{T}$-cell subsets expressing higher levels of CD44, which have a critical role in the development of ileitis in the TNF $\mathrm{THRE}^{\mathrm{ARE}}$ mice. ${ }^{18,19}$ To evaluate if the reduction in ileitis observed in $\mathrm{CrmD} / \mathrm{TNF}^{\triangle \mathrm{ARE}}$ mice correlated with a decrease of CD $44^{+}$ $\mathrm{T}$ cells, we performed flow cytometric analysis in the lamina propria leukocyte (LPL) and in the draining mesenteric lymph node (MLN). As expected, the relative and absolute numbers of $\mathrm{CD} 4{ }^{+} \mathrm{CD} 44^{+} \mathrm{T}$ cells (Figure $5 \mathbf{a}$ and $\mathbf{b}$ ) as well as $\mathrm{CD} 8{ }^{+} \mathrm{CD} 44^{+} \mathrm{T}$ cells (Figure $\mathbf{5 c}$ and $\mathbf{d}$ ) were increased in LPL from TNF $\triangle \mathrm{ARE}$ mice. However, both populations were decreased in the ileum of $\mathrm{CrmD} / \mathrm{TNF}^{\triangle \mathrm{ARE}}$ mice. Similarly, the relative and absolute numbers of $\mathrm{CD} 4^{+} \mathrm{CD} 44^{+}$ $\mathrm{T}$ cells and $\mathrm{CD} 8{ }^{+} \mathrm{CD} 44^{+} \mathrm{T}$ cells in the MLN, which were increased in $\mathrm{TNF}^{\triangle \mathrm{ARE}}$ mice, were significantly decreased in $\mathrm{CrmD} / \mathrm{TNF}^{\triangle \mathrm{ARE}}$ mice to levels compared to WT mice (Figure 5e). Together the results suggest that CrmD expression ameliorates TNF-induced disease by reducing the accumulation of cells critical for development of disease.

\section{CrmD impairs TNF $\alpha$-mediated changes in chemokine expression}

The reduction in the total cell number of leukocytes by $\mathrm{CrmD}$ could be due to the direct interaction of $\mathrm{CrmD}$ with chemokines. CrmD binds to CCL20, CCL22, CCL25, CCL27, CCL28, CXCL12, CXCL13, and CXCL14, but of these, only CCL20, CCL22, and CXCL13 are increased in TNF ${ }^{\triangle A R E}$ mice (Figure 1). CrmD has been shown to inhibit chemotaxis induced by CCL25, ${ }^{12}$ CCL27 (S.M.P. and A.A., unpublished data), and CXCL13 (this study, Figure 2h), but its ability to block the remaining chemokines has not been shown to date. However, even if CrmD could inhibit chemotaxis-induced by CCL20 and CCL22, it would be difficult to explain the drastic changes in some leukocyte populations (i.e., No) observed in the CrmD/ $\mathrm{TNF}^{\triangle \mathrm{ARE}}$ mice, given that these ligands do not affect these cells. An alternative hypothesis would be that the changes were caused by inhibition of TNF $\alpha$-mediated induction of cytokine and chemokine expression.

To test this hypothesis, we compared the levels of TNF $\alpha$, TNF $\propto$ receptor I (TNFRI), TNFRII, and chemokine mRNA in the ileum of WT, TNF ${ }^{\triangle \mathrm{ARE}}$, and $\mathrm{CrmD} / \mathrm{TNF}^{\triangle \mathrm{ARE}}$ mice. As expected, we detected significantly higher levels of TNF $\alpha$ in the ileum of the TNF ${ }^{\triangle \mathrm{ARE}}$ than in WT mice $(P<0.001$, Figure 6a). TNFRI and TNFRII mRNA levels were also upregulated in the TNF ${ }^{\triangle A R E}$ mice $(P<0.001$, Figure 6a). CrmD slightly reduced the expression of TNF $\alpha$ mRNA in the ileum of $\mathrm{CrmD} / \mathrm{TNF}^{\triangle \mathrm{ARE}}$ mice $(P<0.05$, Figure 6a). However, the serum levels of TNF $\alpha$ were not significantly different between $\mathrm{TNF}^{\triangle \mathrm{ARE}}$ mice $\left(56 \pm 38 \mathrm{pg} \mathrm{ml}^{-1}, n=35\right)$ and $\mathrm{CrmD} / \mathrm{TNF}^{\triangle \mathrm{ARE}}$ mice $\left(43 \pm 42 \mathrm{pg} \mathrm{ml}^{-1}, n=10\right)$ indicating again a localized effect of CrmD in the gut. The enhancement in TNF $\alpha$ expression was accompanied by an increase in the expression of certain chemokines. Interestingly, CrmD impaired the induction of CXCL1, CXCL2, CXCL9, CXCL10, CXCL13, CXCL16, CCL2, CCL4, CCL9/10, CCL19, and CCL20 expression (Figure 6b and $\mathbf{c}$, see $P$-values). The fold increase in chemokine expression observed is shown in Table 2. These results suggest that $\mathrm{CrmD}$ inhibits TNF-induced chemokine expression. The fact that $\mathrm{TNF} \alpha$ levels are very low during homeostasis would explain why expression of CrmD did not affect the general recruitment of leukocyte populations during homeostasis in $\mathrm{vCrmD}$ mice, with the exception of $B$ cells, which was probably due to direct chemokine inhibition. This second mechanism may also contribute to the reduction in B cells observed in the CrmD/ $\mathrm{TNF}^{\triangle \mathrm{ARE}}$ mice. 

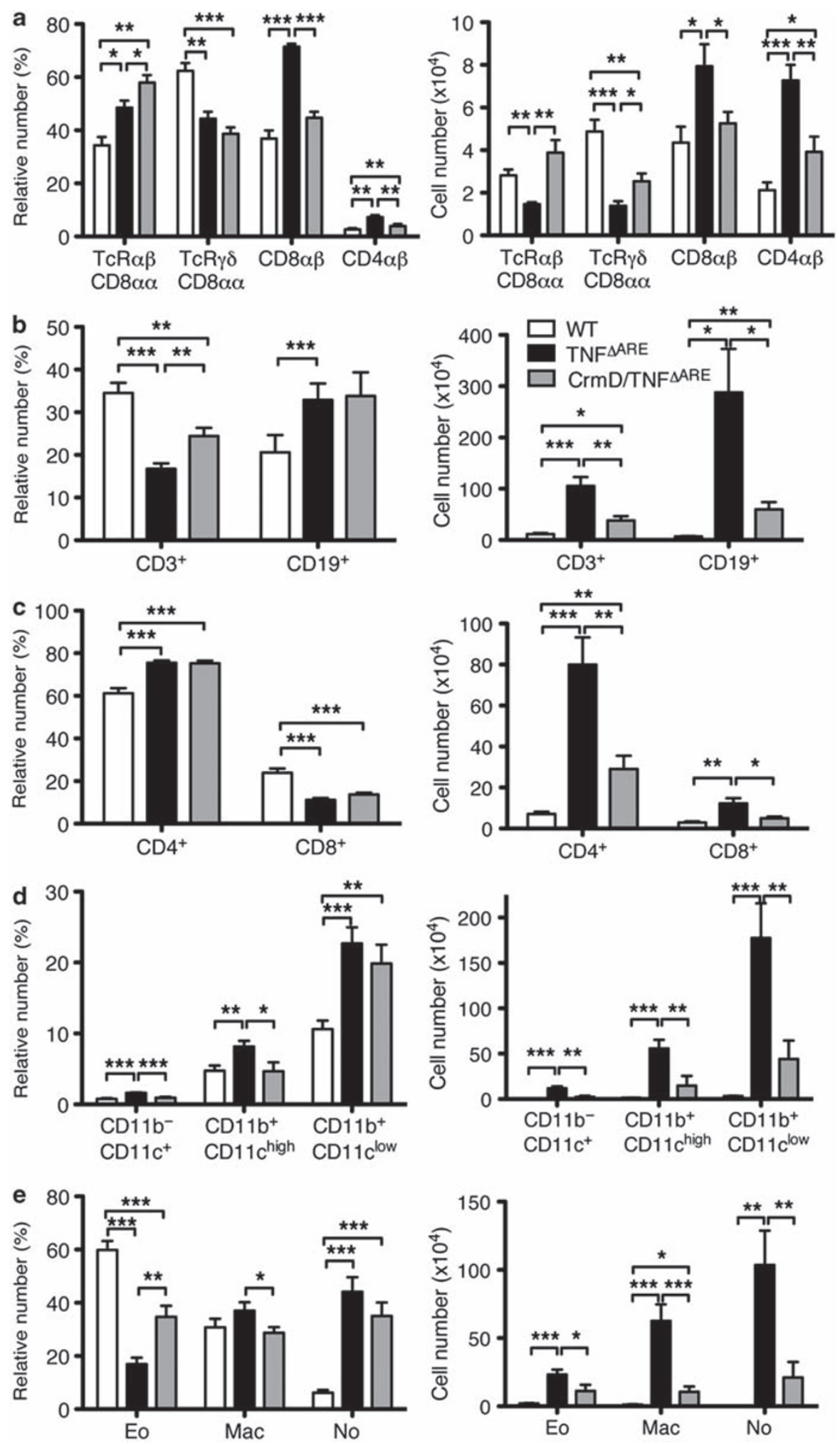

Figure 4 CrmD expression reduces the inflammatory infiltrate observed in the ileum of tumor necrosis factor (TNF) $\triangle A R E$ mice. (a) Relative (left) and absolute (right) numbers of intraepithelial T-cell subsets in wild-type (WT; $n=4)$, TNF ${ }^{\Delta A R E}(n=5)$, and CrmD/TNF ${ }^{\Delta A R E}(n=6)$ mice $\left({ }^{\star} P<0.05,{ }^{* \star} P<0.01\right.$, $\left.{ }^{\star * \star} P<0.001\right)$. (b) Relative (left) and absolute (right) numbers of T and B cells in ileum of WT, TNF $\triangle \mathrm{ARE}$ and CrmD/TNF ${ }^{\Delta A R E}$ mice. (c) Relative (left) and absolute (right) numbers of CD4 and CD8 T cells in ileum of WT, TNF $\triangle A R E$ and CrmD/TNF $\triangle A R E$ mice. (d and e) Relative (left) and absolute (right) numbers of dendritic and myeloid cells (d), Eo, Mac, and No (e) in the ileum of WT, TNF $\triangle$ ARE and CrmD/TNF ${ }^{\Delta A R E}$ mice. (WT, $n=9 ;$ TNF $^{\Delta A R E}, n=12$, CrmD/TNF ${ }^{\triangle A R E} n=11 ;{ }^{*} P<0.05,{ }^{* *} P<0.005,{ }^{* *} P<0.0005$.) No, neutrophils; Eo, eosinophils; Mac, macrophages. 

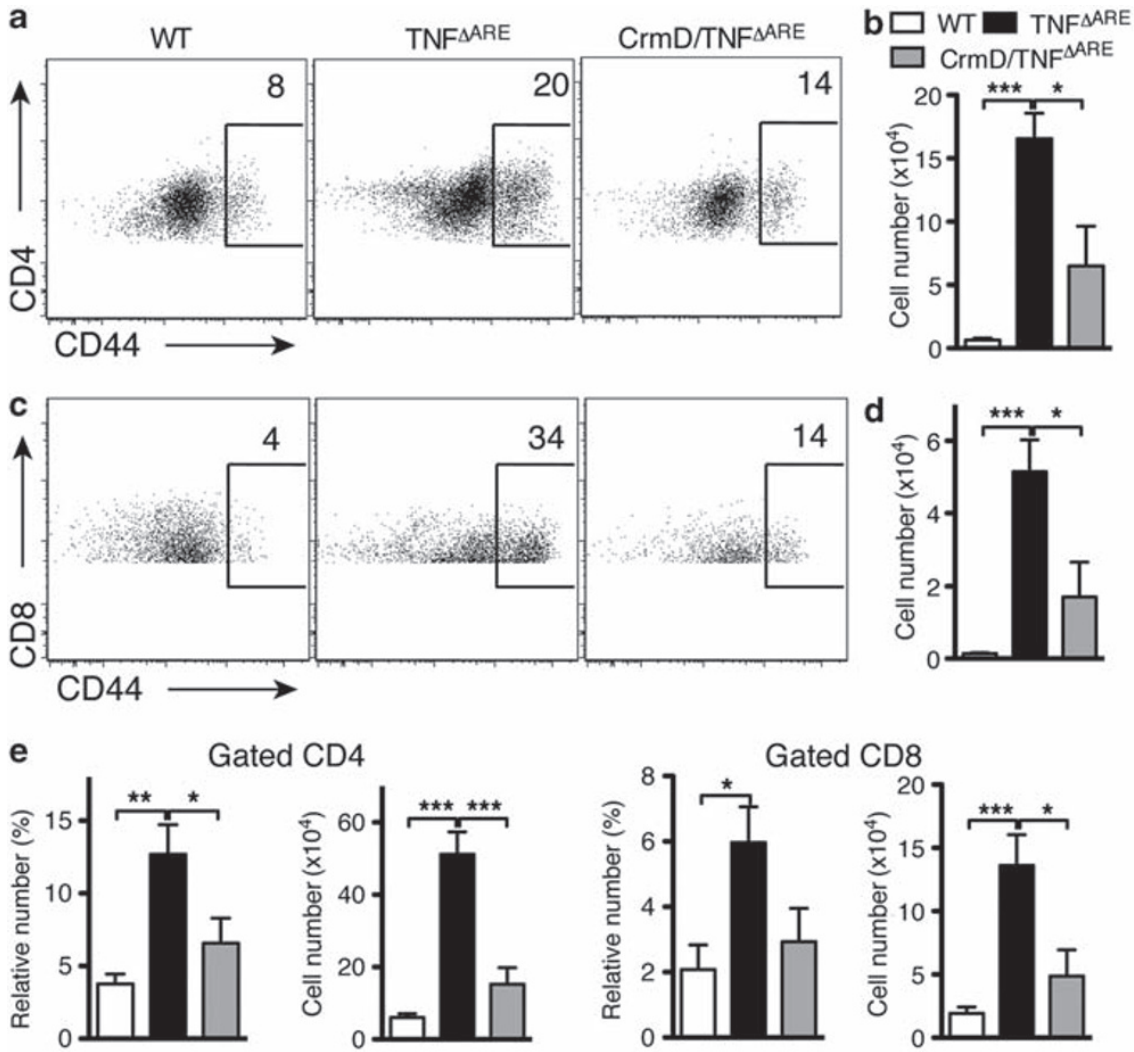

Gated CD4
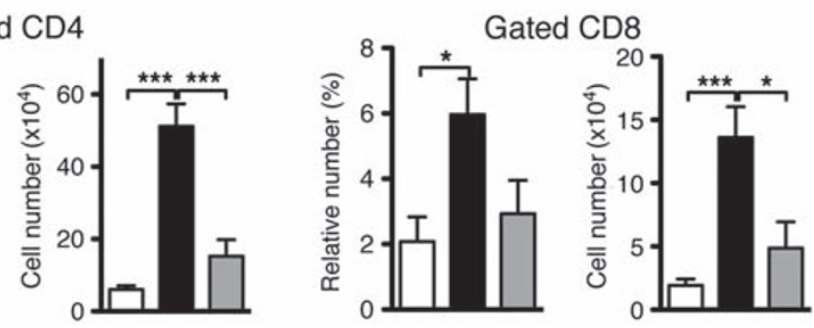

Figure 5 CrmD expression induces a reduction of CD44+ $\mathrm{T}$ cells. (a-d) Representative plot (a and $\mathbf{c})$ and absolute number (b and $\mathbf{d})$ of $\mathrm{CD} 4{ }^{+} \mathrm{CD} 44^{\text {high }}$ (a and $\left.\mathbf{b}\right)$ and CD8 ${ }^{+} \mathrm{CD} 44^{\text {high }}(\mathbf{c}$ and $\mathbf{d})$ cells in the ileum of wild-type (WT; $\left.n=9\right)$, TNF ${ }^{\Delta A R E}(n=12)$, and CrmD/TNF ${ }^{\Delta A R E}(n=11)$ mice $\left({ }^{\star} P<0.05,{ }^{* *} P<0.01,{ }^{* *} P<0.001\right)$. (e) Relative and absolute number of CD4 ${ }^{+} \mathrm{CD} 44^{\text {high }}$ and CD8 ${ }^{+} \mathrm{CD} 44^{\text {high }}$ cells in the mesenteric lymph node (MLN) of WT $(n=7), \operatorname{TNF}^{\triangle A R E}(n=9)$, and $\mathrm{CrmD} / \operatorname{TNF}^{\triangle \mathrm{ARE}}(n=8)$ mice $\left({ }^{\star} P<0.05,{ }^{* \star} P<0.01,{ }^{* * \star} P<0.001\right)$.

\section{DISCUSSION}

In this study, we have used transgenic mice expressing a virusencoded protein to probe the mechanisms underlying TNFdriven inflammatory disease development in the intestine. We show that TNF $\alpha$ has a profound impact on chemokine expression and that expression of $\mathrm{CrmD}$ in the TNF-driven disease background is associated with a marked reduction in the induction of chemokine expression mediated by TNF $\alpha$, indicating inhibition of TNF $\alpha$ function. The reduction in the accumulation of the inflammatory infiltrate could also be due to direct and selective inhibition of chemokine function by $\mathrm{CrmD}$ as observed for B cells. Our results indicate that CrmD expression affects the course of a TNF-driven disease by blocking TNF and thereby reducing chemokine expression and function. They also point to a direct role of chemokines in TNF-driven ileitis, suggesting the possible use of chemokines as new targets for therapy.

The levels of TNF $\alpha$ in the mouse intestine during homeostasis are low (Figure 6a). TNF $\alpha$ is increased during inflammatory conditions, having a pivotal role in the initiation and maintenance of inflammation in the intestine. ${ }^{6,20} \mathrm{TNF}^{\triangle \mathrm{ARE}}$ mice, which express elevated levels of TNF $\alpha$, develop a Crohn's-like disease in the ileum, characterized by massive cellular infiltrates composed of mononuclear cells and polymorphonuclear cells. We hypothesized that these cells were recruited into the ileum because of the local stimulation by TNF of chemokine synthesis. We found that several chemokines were indeed upregulated, including CCL2,
CCL7, CCL8, CCL9/10, CCL17, CCL19, CCL20, CCL21, CCL22 CXCL1, CXCL2, CXCL4, CXCL9, CXCL13, and CXCL16. Many of these chemokines are directly induced by TNF $\alpha .{ }^{21-23}$

To analyze the relevance of TNF $\alpha$ and chemokines in this model of inflammation, we used the virus-encoded molecule CrmD, which exhibit a unique ability to interact simultaneously with both TNF $\alpha$ and some chemokines. ${ }^{12}$ The expression of CrmD under the control of the villin promoter resulted in minor changes in chemokine expression (Figure $\mathbf{2} \mathbf{f}$ and $\mathbf{g}$ ) and did not affect the major leukocyte populations present within the LP during homeostasis, with the exception of $\mathrm{B}$ cells (Figure 2e), suggesting that inhibition of TNF $\alpha$ by $\mathrm{CrmD}$ during homeostasis does not have a significant effect on the recruitment of the different leukocyte populations. Some of these changes, in particular that of CXCL9, may contribute to the reduction in T-cell numbers observed in the $\mathrm{CrmD} /$ $\mathrm{TNF}^{\triangle \mathrm{ARE}}$ mice and to the overall phenotype observed. These results also indicate that direct inhibition of chemokine function by $\mathrm{CrmD}$ does not affect the recruitment and retention in the intestine of most leukocyte populations. The only exception is binding and inhibition of chemokines responsible for B-cell migration, such as CXCL13, a chemokine bound and inhibited by CrmD (ref. 12 and Figure $2 \mathbf{h}$ ).

The expression of CrmD in the intestine of $\mathrm{TNF}^{\triangle \mathrm{ARE}}$ mice dramatically altered the course of disease in the ileum, but not in the joints. The $\mathrm{CrmD} / \mathrm{TNF}^{\triangle \mathrm{ARE}}$ mice had less ileitis than their 

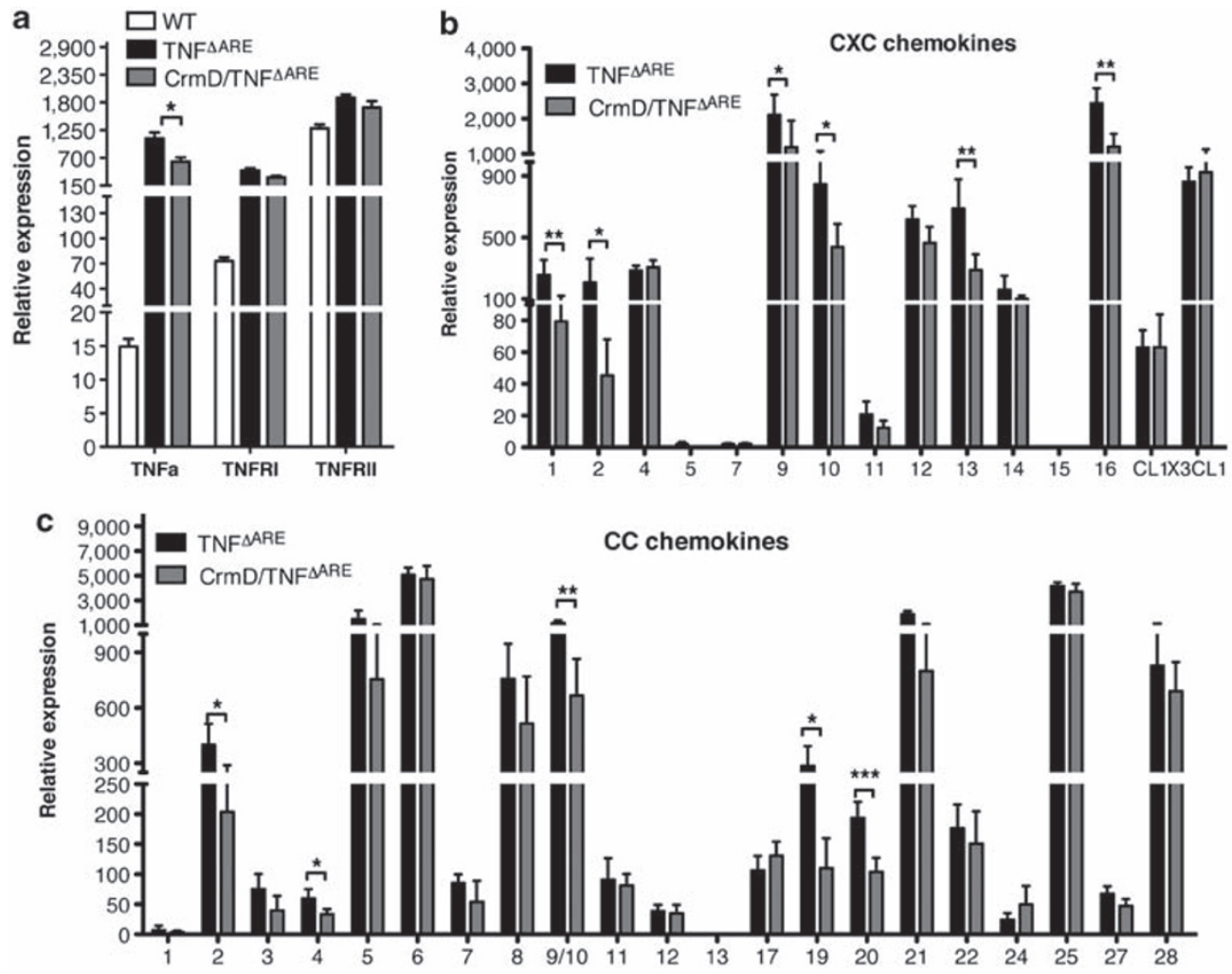

Figure 6 Effect of cytokine response modifier $\mathrm{D}(\mathrm{CrmD})$ on TNF $\alpha$-mediated induction of TNF $\alpha$ and chemokine expression in the ileum of TNF $\triangle$ ARE mice. (a) TNF $\alpha$, TNFRI, and TNFRII mRNA levels in the ileum of wild-type (WT), TNF ${ }^{\triangle A R E}$, and CrmD/TNF ${ }^{\triangle A R E}$ mice. TNF $\alpha$, tumor necrosis factor $\alpha$; TNFR, tumor necrosis factor receptor. (b and $\mathbf{c}$ ) Differential expression of CXC (b) and CC (c) chemokines in the ileum of TNF $\triangle A R E$ and CrmD/ $\mathrm{TNF}^{\triangle A R E}$ mice. The expression of several chemokines is reduced in the ileum of CrmD/TNF $\triangle$ ARE vs. TNF $^{\triangle A R E}$ mice. ( $n=5$, normalized to ubiquitin, ${ }^{\star} P<0.05,{ }^{\star \star} P<0.01,{ }^{\star * \star} P<0.001$.)

$\mathrm{TNF}^{\triangle \mathrm{ARE}}$ littermates, but developed arthritis as the TNF $\triangle \mathrm{ARE}$ mice (Figure 3). Strikingly, the absolute number of inflammatory cells present in the ileum was drastically reduced (Figures 4 and 5). Among the cell populations affected by CrmD are cells critical for ileitis development (Figure 5). These changes were associated with lower levels of TNF $\alpha$ mRNA, and a significant reduction of several chemokines shown to be upregulated in the $\mathrm{TNF}^{\triangle \mathrm{ARE}}$ mice (Figure 6).

CrmD binds simultaneously to TNF $\propto$ through the N-terminal cysteine-rich domain of $\mathrm{CrmD}$ whereas binding to mouse chemokines CCL20, CCL22, CCL27, CCL28, CXCL11, CXCL12 $\beta$, CXCL13, and CXCL14 occurs through the C-terminal domain of $\mathrm{CrmD}^{12}$ (S.M.P and A.A., unpublished data). The C-terminal domain has been also described in other EV proteins and has been termed SECRET (for smallpox virus-encoded chemokine receptor). ${ }^{12}$ Among the chemokines bound by $\mathrm{CrmD}$, only CXCL13, CCL20, and CCL22 were upregulated in the ileum of $\mathrm{TNF}^{\triangle \mathrm{ARE}}$ mice, suggesting that binding and inactivation of CXCL13 and possibly CCL20 by CrmD could account for some of the reduction observed in $\mathrm{B}$ cells in $\mathrm{vCrmD}$ mice and in the $\mathrm{CrmD} / \mathrm{TNF}^{\triangle \mathrm{ARE}}$ compared to the $\mathrm{TNF}^{\triangle \mathrm{ARE}}$ mice. In fact, direct inhibition of CXCL13 by CrmD was observed (Figure $\mathbf{2 h}$ ). However, direct binding of $\mathrm{CrmD}$ to chemokines could not account for the significant reduction observed in absolute numbers of No and Mac, because the chemokines involved in the recruitment of such cells (CXCL1 and CXCL2 for No and
CCL1-CCL9 for monocyte/ $\mathrm{Mac}^{24}$ ) are not bound by CrmD. It is also unlikely that the decrease in T-cell numbers was due to the ability of CrmD to bind CCL25, because recent experiments carried out using mice deficient in CCL25 or its receptor CCR9, do not support a significant role for these molecules in the TNF ${ }^{\triangle A R E}$ model. ${ }^{18}$ Moreover, CCL25 expression is not increased in the TNF ${ }^{\triangle A R E}$ compared to WT mice, and the T-cell numbers are not affected in the $\mathrm{vCrmD}$ intestine.

Our results suggest that the main mechanism accounting for disease reduction in the $\mathrm{CrmD} / \mathrm{TNF}^{\triangle \mathrm{ARE}}$ mice is the local inactivation of TNF $\alpha$ by CrmD, as TNF $\alpha$ is the driving cytokine in the disease process and deletion of TNF $\alpha$ receptors abolishes disease in the TNF ${ }^{\triangle \mathrm{ARE}}$ mice. ${ }^{9}$ We attribute this decrease to reduced amounts of bioactive $\mathrm{TNF} \alpha$ (which can regulate its own expression) and to reduced numbers of TNF $\alpha$-producing leukocytes. The inactivation of TNF $\alpha$ is local, as disease is not reduced in the joints and the systemic levels of TNF $\alpha$ are not decreased in the $\mathrm{CrmD} / \mathrm{TNF}^{\triangle \mathrm{ARE}}$ mice.

Results shown here indicate that the reduction in ileitis is associated with changes in the number of lymphocytes in the intraepithelial and lamina propria (LP) compartments. These findings are important because such cells have important effector roles in the pathogenesis observed in $\mathrm{TNF}^{\triangle \mathrm{ARE}}$ mice. $\mathrm{CD} 8 \alpha \beta$ IEL produce TNF $\alpha$ and interferon $\gamma$ that induce the epithelial barrier dysfunction in TNF ${ }^{\triangle A R E}$ mice, ${ }^{18}$ whereas CD $8 \alpha \alpha$ IEL appear to have regulatory functions. ${ }^{25,26}$ Accumulation of both 
Table 2 Average fold increase in chemokine expression in the ileum of $\mathrm{CrmD/TNF}{ }^{\triangle A R E}$ mice compared to TNF $^{\triangle A R E}$ mice

\begin{tabular}{lccc}
\hline CCL & Fold increase & CXCL & Fold increase \\
\hline 1 & 0.6 & 1 & 0.3 \\
2 & 0.5 & 2 & 0.2 \\
3 & 0.5 & 4 & 1.1 \\
4 & 0.6 & 5 & 0.2 \\
5 & 0.5 & 7 & 1.0 \\
6 & 0.9 & 9 & 0.6 \\
7 & 0.6 & 10 & 0.5 \\
8 & 0.7 & 11 & 0.6 \\
$9 / 10$ & 0.6 & 12 & 0.8 \\
11 & 0.9 & 13 & 0.4 \\
12 & 0.9 & 14 & 0.6 \\
13 & 1.3 & 15 & 0.7 \\
17 & 1.2 & 16 & 0.5 \\
19 & 0.4 & & Fold increase \\
20 & 0.5 & CL & 1.0 \\
21 & 0.4 & 1 & Fold increase \\
22 & 0.9 & & 1.1 \\
24 & 2.0 & $\mathbf{C X 3 C L}$ & \\
25 & 0.9 & 1 & \\
27 & 0.7 & & \\
\hline 28 & 0.8 & & \\
\hline
\end{tabular}

$\mathrm{CD} 4{ }^{+} \mathrm{CD} 44^{+}$and $\mathrm{CD} 8{ }^{+} \mathrm{CD} 44^{+}$effector cells in the LPL leads to maintenance and perpetuation of the ileitis. ${ }^{18,19} \mathrm{CrmD}$ expression in IEC not only decreased the number of effector CD $8 \alpha \beta$ cells in IEL, but also inhibited the accumulation of effector cells in the LPL leading to the generalized reduction in the ileitis observed in the $\mathrm{CrmD} / \mathrm{TNF}^{\triangle \mathrm{ARE}}$ mice.

What could account for these changes? Our results indicate that CrmD expression inhibits the expression of TNF $\alpha$ and several chemokines induced by TNF and that this is associated with pronounced and generalized decrease in leukocyte infiltration in the ileum. Because CrmD is able to bind to and inhibit TNFa, we believe that direct inhibition of TNF $\alpha$ function is key to the reduction in the expression of both TNF $\alpha$ and chemokines that are upregulated in the $\mathrm{TNF}^{\triangle \mathrm{ARE}}$ mice. The reduction in TNF $\alpha$ mRNA levels in $\mathrm{CrmD} / \mathrm{TNF}^{\triangle \mathrm{ARE}}$ mice (compared to those found in $\mathrm{TNF}^{\triangle \mathrm{ARE}}$ mice) is modest but significant and could be due to reduced recruitment of TNF-secreting leukocytes. The reduced expression and reduced functional activity of TNF $\alpha$ could thus explain the reduced expression of chemokines critical for recruitment of leukocytes to the intestine of $\mathrm{CrmD} / \mathrm{TNF}^{\triangle \mathrm{ARE}}$ mice. The identification of the chemokine subsets implicated in these responses is subject of ongoing investigation in our laboratory. Other possible mechanisms could include direct inhibition by $\mathrm{CrmD}$ of chemokine function as discussed above; reduced vascular activation and reduced expression of non-chemokine chemoattractants.
In summary, we show in this study that gut-specific expression of the ectromelia virus-encoded molecule CrmD significantly attenuates the TNF-induced ileitis observed in TNF ${ }^{\triangle \mathrm{ARE}}$ mice. These results establish that the intestinal pathology observed in the $\mathrm{TNF}^{\triangle \mathrm{ARE}}$ mice is largely caused by local, rather than systemic activity of TNF and suggest that chemokines are important factors controlling disease in this model.

\section{METHODS}

Mice. CrmD was amplified by PCR from ectromelia virus DNA using primers CRMD1 (5'-TAACGTACGGCCGCCACCATGATGAAG ATGACACCATCATACATCTTGTTGG-3') and CRMD2 (5' -TAA ACGCGTTCAATCTCTTTCACAATCATTTGGTGG-3') containing $B s i \mathrm{WI}$ and $M l u \mathrm{I}$ sites, respectively. The amplified product was cloned downstream of the villin promoter ${ }^{27}$ and sequenced to ensure that no mutations were present. The transgene was released with SalI, microinjected into C57BL/6J (The Jackson Laboratory, Bar Harbor, ME) eggs, which were transferred into oviducts of ICR foster mothers (Charles River Laboratories, Wilmington, MA). Identification of the transgenic mice was accomplished by PCR amplification of mouse tail DNA using the following specific primers vCrmD-F (5' -TTCTT CCTCTGGGCCTCAAGCCTGGC-3') and vCrmD-R (5' ${ }^{\prime}$ TTACAT TTCCCATTAATGGGTGTATACGG-3' ${ }^{\prime}$. TNF ${ }^{\triangle A R E}$ mice have been described previously. ${ }^{9} \mathrm{CrmD} / \mathrm{TNF}^{\triangle \mathrm{ARE}}$ mice were obtained by crossing $\mathrm{TNF}^{\triangle \mathrm{ARE}}$ and $\mathrm{vCrmD}$ mice from line 1 . The CrmD/TNF $\triangle \mathrm{ARE}$ mice were genotyped with primers vCrmD-F, vCrmD-R, TNF ${ }^{\triangle A R E}-\mathrm{F}$ (5' ${ }^{\prime}$ TGAGGTGCAATGCACAGCCTTCCTC- $\left.3^{\prime}\right)$, and TNF ${ }^{\triangle A R E}-\mathrm{R}$ (5'-AAAGGTAATTAGGGTTAGGCTCC-3').

Immunostaining. To detect CrmD expression in the jejunum of vCrmD mice, we fixed the tissue in $2 \%$ paraformaldehyde containing $20 \%$ sucrose overnight and froze it in OCT. Immunostaining was performed as previously described. ${ }^{28}$ Briefly, rabbit polyclonal primary antibodies targeted to CrmD were incubated for $1 \mathrm{~h}$ at room temperature, followed by incubation with the appropriate fluorescent-labeled secondary antibodies for $30 \mathrm{~min}$.

Histological scoring. The last $5 \mathrm{~cm}$ of the terminal ileum and joints were fixed by immersion in 10\% phosphate-buffered formalin and then processed for paraffin sections. Routinely, $5 \mu \mathrm{m}$ sections were cut and stained with H\&E and two 1.5-2 cm sections of ileum were histologically evaluated in a blinded manner. A semiquantitative scoring system, described previously ${ }^{29}$ with some modifications, was used to obtain the Histological score. Scores were given for five histological changes in the ileum: (i) inflammatory infiltrates (No, lymphocytes, plasma cells, and Mac in the mucosa and submucosa); (ii) lymphoid aggregates; (iii) villus distortion (flattening and/or widening of normal mucosal villous architecture); (iv) transmural infiltration; and (v) granulomata. Scores were given for four histological changes in the joints: (i) synovial proliferation; (ii) presence of No; (iii) articular cartilage destruction; and (iv) subchondral bone resorption. In addition, the presence or absence of the pannus was noted. Scores ranged from 0 to 3 ( 0 , absent; 1 , mild; 2 , moderate; and 3 , severe) and the total histological score per mouse was calculated by the summation of each parameter score for each mouse (data represented as mean \pm s.e.m.).

Isolation of LPLs and IELs. IEL and LPL were isolated as previously described with some modifications. ${ }^{17}$ Briefly, the section of the intestine to be analyzed was removed, flushed with ice-cold calcium- and magnesium-free Hank's balanced salt solution, and freed of fat, mesentery, and Peyer's patches. The tissue was then cut into small pieces about $2 \mathrm{~cm}$ in length and washed two times with Hank's balanced salt solution and then incubated at $37^{\circ} \mathrm{C}$ with shaking for $20 \mathrm{~min}$ in Hank's balanced salt solution containing $1 \mathrm{mmoll}^{-1}$ dithiothreitol for IEL extraction. Then, the 
tissue was incubated with phosphate-buffered saline with $1.3 \mathrm{~mm}$ EDTA for $1 \mathrm{~h}$ at $37^{\circ} \mathrm{C}$. Fragments of intestine were further incubated in $7 \mathrm{ml}$ of $2 \mathrm{mg} \mathrm{ml}^{-1}$ collagenase D (Roche, Nutley, NJ) in RPMI for $1 \mathrm{~h}$ at $37^{\circ} \mathrm{C}$ and LPLs were isolated after $38 \%$ Percoll density gradient. For the vCrmD mice, the analysis was performed using the whole small intestine and the large bowel in separate preparations. In the case of the TNF $\triangle \mathrm{ARE}$ and $\mathrm{CrmD} / \mathrm{TNF}^{\triangle \mathrm{ARE}}$ mice, only the ileum (distal $10 \mathrm{~cm}$ of the small bowel) was analyzed. Cells from the MLN and Peyer's patch were obtained by homogenizing the tissue using a $70 \mu \mathrm{m}$ cell strainer.

FACS analysis. Cells from LP, IEL, Peyer's patch, or MLN were incubated with Fc block (eBiosciences, San Diego, CA) for $15 \mathrm{~min}$ at room temperature, and were then stained with different antibodies to detect different subsets of leukocytes. The antibodies used were from BD Biosciences (San Jose, CA) and eBiosciences. Events were acquired on a Becton Dickinson FACScan (Becton Dickson, Franklin Lake, NJ) and analyzed using FloJo software (Tree Star, Ashland, OR).

RNA extraction and qPCR. We extracted total RNA from the distal ileum (distal $5 \mathrm{~cm}$ of the small bowel) using the RNeasy Midi Kit (Qiagen, Valencia, CA) according to the manufacturer's instructions. The cDNA obtained from these samples was analyzed by qPCR as previously described. ${ }^{17}$

Chemotaxis assay. Splenocytes were obtained from WT C57BL/6J following standard procedures. mCXCL13 (100 nm; R\&D Systems, Minneapolis, MN) was placed in the lower compartment of 96-well ChemoTx System plates (Neuro Probe, Gaithersburg, MD) with or without affinity-purified recombinant CrmD in RPMI 1640 containing $1 \%$ fetal bovine serum. CrmD was purified as described previously. ${ }^{12}$ Splenocytes were placed on the upper compartment of the 96-well ChemoTx System plate. Both chambers were separated by a $3 \mu \mathrm{m}$ pore size filter. The cells were incubated at $37^{\circ} \mathrm{C}$ during $3 \mathrm{~h}$. After the incubation period, we determined the presence of cells in the lower chamber by light microscopy.

Protein quantitation. TNF $\alpha$ immunoreactivity was measured in the serum and CXCL13, CCL20, and CCL22 levels were measured in intestinal tissue extracts by enzyme-linked immunosorbent assay (R\&D Systems). Enzyme-linked immunosorbent assay was performed according to the manufacturer's instructions. The amount of chemokine is

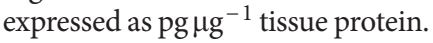

Statistical analysis. Statistical analysis of the data was carried out using Prism 4.0c (GraphPad Software, San Diego, CA). Data were given as mean \pm s.e.m. unless otherwise stated. Unpaired Student's $t$-test was used to determine statistical significance. Differences were considered significant when $P<0.05$.

Author contributions: A.V.B. and S.L.: conception and design of the study; A.V.B., A.M., L.S., F.M., R.A.G., N.T., G.C.F., and S.L.: generation, collection, assembly, analysis, and/or interpretation of data; A.A. and G.K.: material support; A.V.B., A.M., and S.L.: drafting of the paper; N.H., R.A.G., L.M., G.K., and A.A.: revision of the paper; A.V.B., A.M., and S.L.: approval of the final version of the paper.

SUPPLEMENTARY MATERIAL is linked to the online version of the paper at http://www.nature.com/mi

\section{ACKNOWLEDGMENTS}

We thank Yasmin G. Hernandez for technical help and Jay Unkeless and Ali Alejo for discussions and critical reading of the paper. We thank Sergio M. Pontejo for providing the anti-CrmD antibody. This work was supported by NIH grants P01 DK072201 (S.A.L. and L.M.), New York Crohn's Foundation and CCFA (L.M.), and from the Instituto de Salud Carlos III, Spanish Ministry of Health (A.V.-B.).

\section{DISCLOSURE}

A. Alcami is an inventor of a patent application on the potential therapeutic use of the anti-chemokine activity of CrmD.

\section{(C) 2010 Society for Mucosal Immunology}

\section{REFERENCES}

1. Dahan, S., Roth-Walter, F., Arnaboldi, P., Agarwal, S. \& Mayer, L. Epithelia: lymphocyte interactions in the gut. Immunol. Rev. 215, 243-253 (2007).

2. Van Deventer, S.J. Tumour necrosis factor and Crohn's disease. Gut 40, 443-448 (1997).

3. Piguet, P.F., Vesin, C., Guo, J., Donati, Y. \& Barazzone, C. TNF-induced enterocyte apoptosis in mice is mediated by the TNF receptor 1 and does not require p53. Eur. J. Immunol. 28, 3499-3505 (1998).

4. Papadakis, K.A. \& Targan, S.R. Role of cytokines in the pathogenesis of inflammatory bowel disease. Annu. Rev. Med. 51, 289-298 (2000).

5. Behm, B.W. \& Bickston, S.J. Tumor necrosis factor-alpha antibody for maintenance of remission in Crohn's disease. Cochrane Database Syst. Rev. (2008). Issue No. A. Art. No. CD006893.

6. Brown, S.J. \& Mayer, L. The immune response in inflammatory bowel disease. Am. J. Gastroenterol. 102, 2058-2069 (2007).

7. Yadav, P.K. \& Liu, Z. Current strategies for the treatment of ulcerative colitis. Recent Pat. Inflamm. Allergy Drug Discov. 3, 65-72 (2009).

8. Pizarro, T.T., Arseneau, K.O., Bamias, G. \& Cominelli, F. Mouse models for the study of Crohn's disease. Trends Mol. Med. 9, 218-222 (2003).

9. Kontoyiannis, D., Pasparakis, M., Pizarro, T.T., Cominelli, F. \& Kollias, G. Impaired on/off regulation of TNF biosynthesis in mice lacking TNF AU-rich elements: implications for joint and gut-associated immunopathologies. Immunity 10, 387-398 (1999).

10. Kontoyiannis, D., Boulougouris, G., Manoloukos, M., Armaka, M., Apostolaki, M. \& Pizarro, T. et al. Genetic dissection of the cellular pathways and signaling mechanisms in modeled tumor necrosis factor-induced Crohn's-like inflammatory bowel disease. J. Exp. Med. 196, 1563-1574 (2002).

11. Zlotnik, A. \& Yoshie, O. Chemokines: a new classification system and their role in immunity. Immunity 12, 121-127 (2000).

12. Alejo, A., Ruiz-Arguello, M.B., Ho, Y., Smith, V.P., Saraiva, M. \& Alcami, A. A chemokine-binding domain in the tumor necrosis factor receptor from variola (smallpox) virus. Proc. Natl. Acad. Sci. USA 103, 5995-6000 (2006).

13. Ruiz-Argüello, M.B., Alejo, A.\& Alcami, A. Secreted tumour necrosis factor inhibitors encoded by poxviruses. In SGM Symposium 64 (Digard, P.E., Nash, A.A., \& Randall, R.E., eds) (Cambridge University Press, 2005).

14. Gileva, I.P. et al. Properties of the recombinant TNF-binding proteins from variola, monkeypox, and cowpox viruses are different. Biochim. Biophys. Acta 1764, 1710-1718 (2006).

15. Shang, L. et al. Toll-like receptor signaling in small intestinal epithelium promotes B-cell recruitment and IgA production in lamina propria. Gastroenterology 135, 529-538 (2008).

16. Kunkel, E.J., Campbell, D.J. \& Butcher, E.C. Chemokines in lymphocyte trafficking and intestinal immunity. Microcirculation 10, 313-323 (2003).

17. Shang, L. et al. Expression of the chemokine binding protein $M 3$ promotes marked changes in the accumulation of specific leukocytes subsets within the intestine. Gastroenterology 137, 1006-1018, 1018.e1-1018.e3 (2009).

18. Apostolaki, M. et al. Role of beta7 integrin and the chemokine/chemokine receptor pair CCL25/CCR9 in modeled TNF-dependent Crohn's disease. Gastroenterology 134, 2025-2035 (2008).

19. Collins, C.B. et al. CD44 deficiency attenuates chronic murine ileitis. Gastroenterology 135, 1993-2002 (2008)

20. Andoh, A., Yagi, Y., Shioya, M., Nishida, A., Tsujikawa, T. \& Fujiyama, Y. Mucosal cytokine network in inflammatory bowel disease. World J. Gastroenterol. 14, 5154-5161 (2008).

21. Wright, T.W., Pryhuber, G.S., Chess, P.R., Wang, Z., Notter, R.H. \& Gigliotti, F. TNF receptor signaling contributes to chemokine secretion, inflammation, and respiratory deficits during Pneumocystis pneumonia. J. Immunol. 172, 2511-2521 (2004).

22. Roach, D.R., Bean, A.G., Demangel, C., France, M.P., Briscoe, H. \& Britton, W.J. TNF regulates chemokine induction essential for cell recruitment, granuloma formation, and clearance of mycobacterial infection. J. Immunol. 168, 4620-4627 (2002).

23. Jamieson, T. et al. The chemokine receptor $D 6$ limits the inflammatory response in vivo. Nat. Immunol. 6, 403-411 (2005). 


\section{ARTICLES}

24. Le, Y., Zhou, Y., Iribarren, P. \& Wang, J. Chemokines and chemokine receptors: their manifold roles in homeostasis and disease. Cell Mol. Immunol. 1, 95-104 (2004).

25. Das, G., Augustine, M.M., Das, J., Bottomly, K., Ray, P. \& Ray, A. An important regulatory role for $\mathrm{CD} 4+\mathrm{CD} 8$ alpha alpha T cells in the intestinal epithelial layer in the prevention of inflammatory bowel disease. Proc. Natl. Acad. Sci. USA 100, 5324-5329 (2003).

26. Poussier, P., Ning, T., Banerjee, D. \& Julius, M. A unique subset of selfspecific intraintestinal T cells maintains gut integrity. J. Exp. Med. 195, 1491-1497 (2002)
27. Pinto, D., Robine, S., Jaisser, F., El Marjou, F.E. \& Louvard, D. Regulatory sequences of the mouse villin gene that efficiently drive transgenic expression in immature and differentiated epithelial cells of small and large intestines. J. Biol. Chem. 274, 6476-6482 (1999).

28. Martin, A.P., Canasto-Chibuque, C., Shang, L., Rollins, B.J. \& Lira, S.A. The chemokine decoy receptor $\mathrm{M} 3$ blocks $\mathrm{CC}$ chemokine ligand 2 and $\mathrm{CXC}$ chemokine ligand 13 function in vivo. J. Immunol. 177, 7296-7302 (2006).

29. Burns, R.C., Rivera-Nieves, J., Moskaluk, C.A., Matsumoto, S., Cominelli, F. \& Ley, K. Antibody blockade of ICAM-1 and VCAM-1 ameliorates inflammation in the SAMP-1/Yit adoptive transfer model of Crohn's disease in mice. Gastroenterology 121, 1428-1436 (2001). 